\title{
Sistem Deteksi Kebocoran Gas Sederhana Berbasis Arduino Uno
}

\author{
Nurul Hidayat $\left.{ }^{\star}\right)$, Samsul Hidayat, Nugroho Adi Pramono, Ulfa Nadirah \\ Jurusan Fisika, Fakultas Matematika dan Ilmu Pengetahuan Alam, Universitas Negeri Malang \\ *Email: nurul.hidayat.fmipa@um.ac.id
}

DOI: https://doi.org/10.21107/rekayasa.v13i2.6737

\begin{abstract}
Simple Gas Leakage Detection System Based on Arduino Uno
\section{ABSTRACT}

The use of gas in various aspects of human life nowadays is inevitable, ranging from the needs of household scales to industries. As an effort to increase the prevention of occupational accidents due to gas leakage, control of gas leakage becomes a vital action. Therefore, this paper discusses the response of MQ2, MQ3, and MQ5 gas sensors to gases and smokes. The ATMega328 microcontroller ran the three gas sensors with the Arduino Uno module. As an actuator, buzzers were used as audio signal senders and LEDs as a basis for visual information related to reminders of excess gas detected by MQ2, MQ3, and MQ5. The physical mechanism, when the gas sensor detects the presence of excess gas, then the sound signal from the buzzer could be activated in such a way that it can be used as an early indication of the presence of leakage of gas. Generally, MQ2, MQ3, and MQ5 gas sensors performed slightly differently in responding to the presence of gases and smokes. In turn, the results of this study are designed as relevant information in selecting the type of gas sensor as needed.
\end{abstract}

Keywords: Gas sensor, Microcontroller, MQ2, MQ3, MQ5, Simple instrumentation.

\section{ABSTRAK}

Penggunaan gas di berbagai sendi kehidupan manusia sekarang ini tidak dapat terhindarkan, mulai dari kebutuhan skala rumah tangga hingga industri. Dalam upaya meningkatkan pencegahan terjadinya kecelakaan kerja akibat kebocoran gas, kontrol terhadap kebocoran gas merupakan sebuah tindakan yang vital. Oleh karena itu, makalah ini membahas respon sensor gas MQ2, MQ3, dan MQ5 terhadap gas dan asap. Ketiga sensor gas tersebut dijalankan oleh mikrokontroler ATMega328 dengan modul Arduino Uno. Sebagai aktuator, buzzer digunakan sebagai pengirim sinyal audio dan LED sebagai basis informasi visual terkait pengingat adanya gas berlebih yang terdeteksi oleh MQ2, MQ3, dan MQ5. Secara mekanisme fisis, ketika sensor gas mendeteksi adanya gas berlebih, maka sinyal suara dari buzzer akan aktif sedemikian rupa sehingga dapat digunakan sebagai indikasi dini terhadap keberadaan atau kebocoran gas. Secara umum, sensor gas MQ2, MQ3, dan MQ5 memiliki respon yang sedikit berbeda pada jenis asap dan gas yang berbeda. Pada gilirannya nanti, hasil dari penelitian ini dirancang sebagai informasi penting dalam pemilihan jenis sensor gas sesuai kebutuhan.
\end{abstract}

Kata Kunci: Instrumentasi sederhana, MQ2, MQ3, MQ5, Mikrokontroller, Sensor gas.

\section{PENDAHULUAN}

Gas sangat penting untuk kehidupan manusia, pada rumah tangga gas digunakan sebagai bahan bakar minyak yang telah dikonversikan ke liquefied petroleum gas (LPG) (Pranadji et al., 2010). Selain pada skala kehidupan rumah tangga, gas juga banyak digunakan pada industri dan lingkungan medis. Dengan kata lain, gas sangat penting bagi kehidupan manusia. Penggunaan gas dapat memberikan pengaruh baik dan buruk, pengaruh baiknya adalah peningkatan efektivitas produksi panas yang lebih bersih serta pengurangan konsentrasi zat pengotor di udara. Adapun sisi negatifnya adalah bahwa gas memiliki sifat yang mudah terbakar. Sifat inilah yang mampu mengakibatkan ledakan yang berdampak buruk bagi manusia dan lingkungan. Di samping itu, kandungan emisi gas

\section{Article History:}

Received: February, $11^{\text {th }}$ 2020; Accepted: May, $10^{\text {th }} 2020$

REKAYASA ISSN: 2502-5325 has been Accredited by Ristekdikti (Arjuna) Decree: No. 23/E/KPT/2019 August $8^{\text {th }}$, 2019 effective until 2023 rumah kaca dan paparan gas pada tubuh manusia juga membahayakan (Hakim \& Yonatan, 2017).

Untuk mencegah terjadinya dampak negatif gas bagi kesehatan dan keselamatan manusia, perlu antisipasi dini dengan alat pendeteksi gas yang berguna untuk merespon gas dan asap pada rumah tangga maupun lingkungan. Prototipe pendeteksi kebocoran gas yang paling efektif adalah dengan menggunakan mikrokontroler Arduino UNO R3. Modul ini adalah papan mikrokontroller sumber terbuka (open source) yang dilengkapi dengan pin input/otput (I/O) analog dan digital yang dapat dihubungkan dengan rangkaian dan papan pelindung lainnya. Papan Arduino UNO R3 memiliki 14 pin digital dan 6 pin analog (Sudhan et al., 2015). Arduino

\section{Cite this as:}

Hidayat, N., Hidayat, S., Pramono, N.A., \& Nadirah, U. (2020). Sistem Deteksi Kebocoran Gas Sederhana Berbasis Arduino Uno. Rekayasa, 13(2), 181-186.

https://doi.org/10.21107/rekayasa.v13i2.6737 
UNO R3 digunakan untuk memprogram data. Arduino UNO R3 terdiri dari perangkat keras berupa modul mikrokontroller yang telah siap untuk digunakan. Kelebihan dari Arduino adalah mudah untuk digunakan karena rangkaian dan program sudah tertanam dalam satu board (Lavelle, 2018). Pada penelitian ini, sensor MQ2, MQ3, MQ5, buzzer dan LED dipilih untuk dikaji performanya terhadap respon kebocoran gas.

Sensor gas MQ2 mudah diaplikasikan dan sedikit menggunakan pin pada mikrokontroller. Dalam MQ2, terdapat alat pemanas berukuran kecil dengan sensor berbasis elektrokimia yang mudah bereaksi dengan beberapa gas, dengan luaran berupa tingkat intensitas gas (Nurnaningsih, 2018). MQ5 adalah jenis sensor semikonduktor yang berfungsi untuk mendeteksi adanya gas, timah dioksida ( $\mathrm{SnO} 2)$ adalah bahan penting bagi sensor MQ5 (Miftakul Amin et al., 2018). Sensor gas MQ5 digunakan untuk mendeteksi gas pada LPG, karena sensor MQ5 sensitif terhadap Gas alam dan LPG sehinggan sensitifitas rendah terhadap pembacaan alkohol dan asap rokok dengan luaran tegangan analog. Sensor MQ5 dapat mendeteksi konsentrasi asap dan gas dengan rentang 300-10.000 ppm (Ikrom et al., 2016). Sensor MQ3 lebih banyak digunakan untuk mendeteksi alkohol dan etanol dilihat dari tingkat sensitifitasnya. Luaran dari MQ3 sendiri berupa tegangan analog, antarmuka yang digunakan tidak rumit, dapat menggunakan konverter analog ke digital untuk memberikan respon terhadap tegangan 0-3,3 volt (Perdana et al., 2016). Untuk memperoleh sebuah mekanisme sensor yang baik, maka diperlukanlah buzzer. Komponen elektronika yang mampu mengkonversi sinyal listrik menjadi sinyal suara ini sangat diperlukan sebagai isyarat bagi respon sensor pada nilai-nilai tertentu (Sari, Kartika, Cucu Suhery, 2015). Dengan kata lain, buzzer dapat digunakan untuk menarik perhatian penggunakan apabila sensor gas mendeteksi adanya kebocoran gas (Putra et al., 2017).

\section{METODE PENELITIAN}

Sensor gas MQ2, MQ3 dan MQ5 dipilih untuk kebutuhan pengujian gas. Sensor-sensor tersebut bekerja berdasarkan perintah pemrograman dari Arduino UNO R3. Sebagai aktuator, sinyal suara dari buzzer dan cahaya dari lampu LED (light emitting diode) digunakan untuk mengidentifikasi adanya kebocoran gas. Agar prototipe sensor gas sederhana ini bekerja dengan baik, resistor $220 \Omega$ dipasang mengikuti jumlah LED. Mikrokontroller ATMega328 pada Arduino UNO R3 memiliki 32 bit port atau $4 \times 8$ bit. Bit-bit pada mikrokontroller tidak semua digunakan dalam prototipe ini. Fungsi bit-bit pada mikrokontroller yang digunakan diantaranya yaitu: Pin positif 8:1/O, 9:1/O, dan $10: 1 / 0$, secara berturut-turtut digunakan dihubungkan dengan LED kuning, merah, dan hijau. Semua lampu ini berfungsi sebagai indikator kebocoran gas. Sementara itu, pin 11:I/O dihubungkan dengan buzzer sebagai penenda kebocoran gas. Pin A0: digunakan sebagai pembaca sensor gas dalam bentuk analog. Pin VCC $5 v$ dan GND: dihubungkan pada kaki sensor gas berfungsi sebagai sumber tegangan positif dan negatif pada sensor gas. Pin GND: negatif untuk kaki LED kuning, merah, hijau dan buzzer.

Mekanisme kerja alat pendeteksi kebocoran gas ini, secara prinsip, melibatkan 3 jenis sensor gas dengan tipe yang berbeda sebagai indikator perbandingan tingkat sensitifitas. Pengujian yang dilakukan ada 2 yaitu menggunakan gas korek api dan asap, jenis asap yang digunakan asap rokok dan asap korek api dengan batas waktu 15 detik. Jarak tabung gas dengan alat prototipe dusahakan dekat untuk memudahkan alat mendeteksi gas secara akurat. Sensor gas yang digunakan adalah sensor gas MQ2, MQ3 dan MQ5. Pengujian menggunakan sensor gas bertujuan untuk mendeteksi adanya keberadaan gas (Sihombing et al., 2018). Lampu LED yang digunakan menggunakan 3 lampu LED yang berbeda, LED warna hijau menandakan adanya kebocoran gas dengan $200>$ nilai konsentrasi gas < 250, LED warna kuning menandakan adanya kebocoran gas dengan $250>$ nilai konsentrasi gas < 300 dan LED warna merah menandakan adanya kebocoran gas dengan nilai konsentrasi gas $>300$. Semua satuan konsentrasi gas pada penelitian ini adalah arbitrary unit (a.u.). Buzzer digunakan sebagai alarm, apabila lampu LED nyala, maka buzzer juga nyala, berarti ada gas dan asap yang terdeteksi. Pada keadaan lampu LED semua mati buzzer juga ikut mati, pada keadaan lampu LED warna hijau menyala, buzzer juga ikut menyala dengan suara bunyi 
pelan, pada keadaan lampu LED warna kuning menyala, buzzer juga ikut menyala dengan suara bunyi sedang dan pada keadaan lampu LED warna merah menyala, buzzer juga ikut menyala dengan suara bunyi cepat. Alur penelitian ini dapat dilihat pada Gambar 1.

\section{HASIL DAN PEMBAHASAN}

Prototipe sistem deteksi kebocoran gas dapat dilihat pada Gambar 2 yang dapat digunakan pada rumah-rumah maupun pabrik yang ditempatkan cukup dekat dengan gas dan asap. Sensor gas dibangun dengan mengikuti rangkaian pada Gambar 3. MQ2, MQ3, dan MQ5 terhubung secara berturut-turut pada pin $\mathrm{A} 0$, GND dan 5V, buzzer terhubung dengan pin 11 , resistor terhubung dengan kaki negatif LED. LED merah, kuning, dan hijau secara berturut-turut terhubung dengan pin 9, 8 dan 10 pada Arduino UNO R3.
Tabel 1. Batas Kadar Gas.

\begin{tabular}{cc}
\hline $\begin{array}{c}\text { Kadar Gas } \\
\text { (Skala)* }\end{array}$ & Batas Kadar Gas (× a.u.) \\
\hline 0 & $\times<200$ \\
1 & $200 \geq x<250$ \\
2 & $250 \geq<300$ \\
3 & \\
\hline *skala korek api
\end{tabular}

Tabel 2. Pengujian Sensor pada Gas Korek Api.

\begin{tabular}{|c|c|c|c|c|c|c|}
\hline \multirow{3}{*}{$\begin{array}{c}\text { Kadar } \\
\text { gas } \\
\text { (skala) } \\
\star\end{array}$} & \multicolumn{3}{|c|}{ Buzzer } & \multicolumn{3}{|c|}{ Lampu LED } \\
\hline & MQ2 & $\mathrm{MQ}$ & MQ5 & MQ2 & $\mathrm{MQ}$ & MQ5 \\
\hline & & 3 & & & 3 & \\
\hline 0 & Mati & Mati & Mati & Mati & Mati & Mati \\
\hline 1 & Nyala & Mati & Nyala & Kuning & Mati & Merah \\
\hline 2 & Nyala & Mati & Nyala & Merah & Mati & Merah \\
\hline 3 & Nyala & Mati & Nyala & Merah & Mati & Merah \\
\hline
\end{tabular}

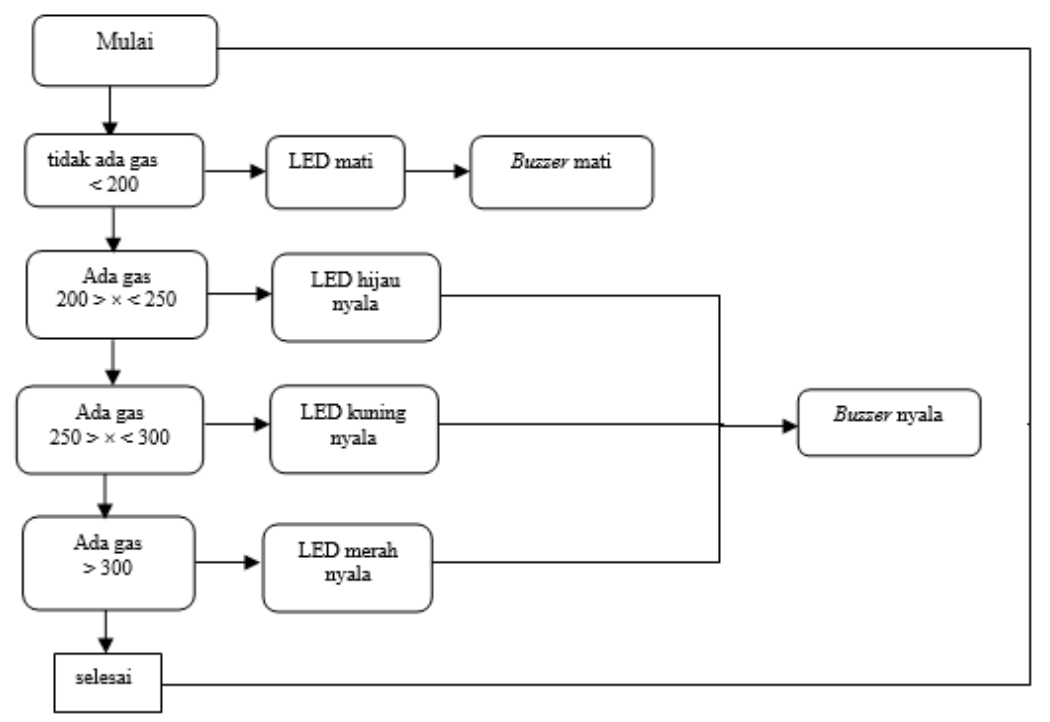

Gambar 1. Alur Kerja Pendeteksi Kebocoran Gas Mikrokontroller Arduino Uno R3.

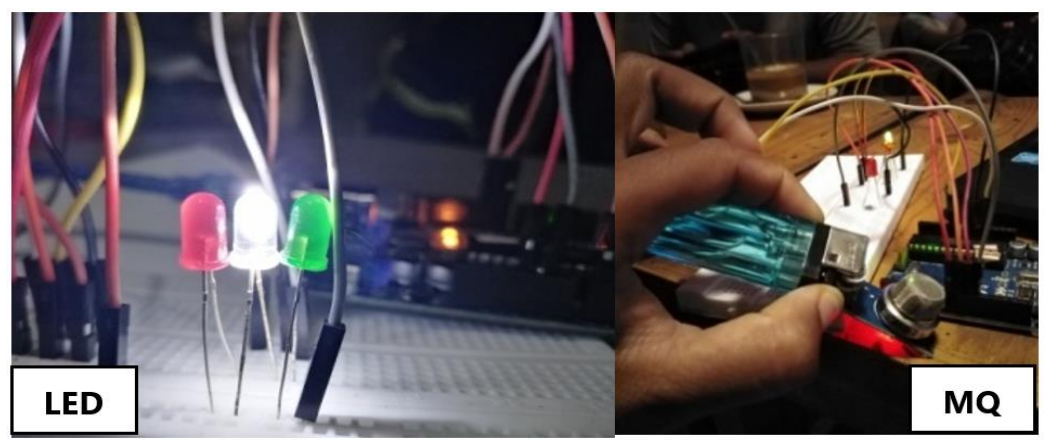

Gambar 2. Tampilan Prototipe Detektor Sensor Gas. 


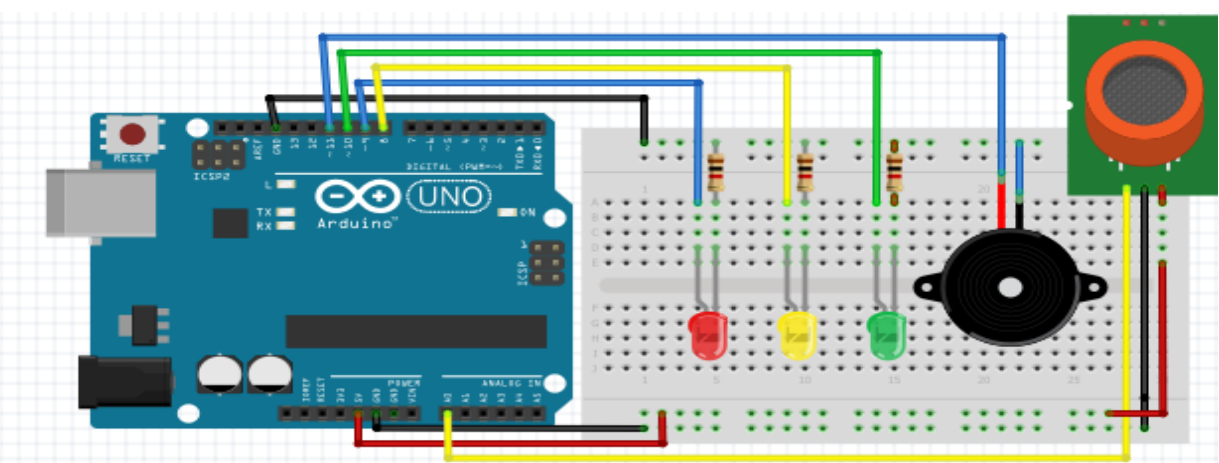

Gambar 3. Rangkaian Sensor Gas Sederhana menggunakan Mikrokontroller Arduino UNO R3.

Tabel 3. Pengujian Sensor MQ3 pada Asap Rokok dan Obat Nyamuk

\begin{tabular}{ccc}
\hline Pengujian & Buzzer & Lampu LED \\
\hline Asap rokok & Nyala & Merah \\
Asap obat nyamuk & Nyala & Merah \\
\hline
\end{tabular}

Tabel 1 menunjukkan klaterisasi konsentrasi pembacaan pada sensor MQ2, MQ3, dan MQ5 yang telah disesuaikan dengan skala kadar gas yang ada pada korek api komersial. Dengan demikian, respon buzzer dan LED sebagai aktuator dapat dikuantifikasi untuk mendapatkan data yang dapat dipercaya. Untuk indikator LED warna hijau menggunakan konsentrasi gas berada di antara 200 a.u. hingga 250 a.u., indikator LED kuning dengan konsentrasi gas di atas 250 a.u.hingga 300 a.u. dan indikator LED merah di atas 300 a.u. Dengan kata lain, by default, skala 1, 2, dan 3 pada gas korek api akan bersesuaiakan dengan respon LED dengan warna hijau, kuning, dan merah, secara berturut-turut. Meskipun demikian, pada akhirnya masing-masing sensor akan menghasilkan respon yang dapat sama atau berbeda satu sama lain. Hasil pengukuran oleh ketiga sesor MQ2, MQ3, dan MQ5 diberikan pada Tabel 2.

Berdasarkan Tabel 2, diperoleh data bahwa kedua aktuator menunjukkan respon "mati" pada buzzer dan LED. Kondisi ini sangat fisis karena memang tidak ada gas yang dikeluarkan oleh korek api. Buzzer mulai menyala ketika gas diatur pada skala 1 hingga skala 3 untuk sensor MQ2 dan MQ5, tetapi tidak untuk sensor MQ3. Sensor yang terakhir ini tidak memberikan respon terhadap keberadaan gas korek api baik ketika aktuator yang digunakan adalah buzzer maupun LED. Lebih lanjut, untuk sensor MQ2, ketika kadar gas korek api diatur pada skala 1, lampu LED hijau menyala pada 5 detik pertama dan kemudian meningkat hingga LED kuning menyala. Selanjutnya, ketika kadar gas pada korek api diatur pada skala 2, mula-mula lampu LED hijau menyala pada 2 detik pertama, namun kemudian hasil pembacaan monitor meningkat tajam dan lampu LED merah menyala hingga pengukuran detik terakhir. Sedangkan ketika menggunakan kadar gas dengan skala 3, lampu LED yang menyala adalah dari LED hijau langsung menuju merah. Hasil pengukuran ini wajar karena ketika gas korek api diatur pada skala tertentu, butuh waktu untuk gas masuk ke sensor sehingga pembacaannya bermula dari hijau (dalam waktu singkat) ke kuning (stabil) untuk skala 1 atau dari hijau (sebentar) ke merah (stabil) untuk skala 2 dan 3 pada sensor gas MQ2. Secara prinsip, sertiap sensor butuh memiliki waktu tunda (Dominguez-Pumar et al., 2016). Sebagai pembanding, pengujian dengan pengaturan kadar gas korek api pada MQ5 mulai dari skala 1 sampai skala 3 langsung menunjukkan hasil bahwa lampu LED merah yang menyala. Temuan dalam penelitian ini menunjukkan bahwa sensor MQ2 adalah yang paling sensitif karena mampu memberikan data degradasi LED yang lebih distintif. Oleh karena itu MQ2 banyak dikaji untuk diaplikasikan sebagai detektor kebocoran gas yang efektif (Omar et al., 2019). Di sisi lain, sensor MQ3 adalah sensor yang paling tidak responsif. Hal ini dikarenakan sensor MQ3 ditujukan untuk deteksi gas alkohol atau etanol, dan asap (Ashwini et al., 2018). Tabel 3 menunjukkan pengujian asap obat nyamuk dengan asap rokok untuk sensor gas MQ3, sensor ini memberikan respon pada buzzer yang menyala dan LED berwarna merah. Ini menandakan bahwa sensor MQ3 responsif 
terhadap asap seperti yang dilaporkan dalam literasi ilmiah yang lain (Binu et al., 2019).

\section{KESIMPULAN}

Alat pendeteksi kebocoran gas yang menggunakan nyala lampu LED dan suara buzzer sebagai indikator peringatan tekanan kebocoran gas dapat mendeteksi tingkat kebocoran gas pada konsentrasi gas di atas 200 a.u.. Perbedaan kadar gas juga dapat diidentifikasi melalui respon bunyi buzzer dan nyala lampu LED dengan sensor gas MQ2 dan MQ5, tetapi tidak pada sensor MQ3 yang tidak menunjukkan nyala lampu pada LED maupun bunyi pada buzzer. Ini dikarenakan sensitifitas sensor MQ3 adalah pada alkohol, etanol, dan asap. Sehingga pada pengujian asap dengan menggunakan asap rokok dan obat nyamuk, sensor MQ3 menunjukkan bahwa nilai konsentrasi yang dihasilkan lebih tinggi dibandingkan dengan sensor MQ2 dan MQ5. Jika dibandingkan, sensor gas MQ2 paling efektif untuk detektor kebocoran gas.

\section{UCAPAN TERIMA KASIH}

Penulis menyampaikan terima kasih yang sebesar-besarnya kepada Universitas Negeri Malang atas bantuan dana melalui Hibah Penelitian Skirpsi dengan nomor kontrak 4.3.451/UN32.14.1/LT/2020.

\section{DAFTAR PUSTAKA}

Ashwini, S. R., Chethan, Shivashankar, Harish, B. R., Karthik, R., \& Bafna, K. D. (2018). Wireless sensors network for environmental radiation monitoring using IOT. 2018 3rd IEEE International Conference on Recent Trends in Electronics, Information and Communication Technology, RTEICT 2018 - Proceedings. https://doi.org/10.1109/RTEICT42901.20 18.9012324

Binu, P. K., Sredhey, K. J., \& Anuvind, R. S. (2019). An lot Based Safety and Security Mechanism for Passenger Vehicles. 2019 2nd International Conference on Intelligent Computing, Instrumentation and Control Technologies, ICICICT 2019. https://doi.org/10.1109/ICICICT46008.2 019.8993177

Dominguez-Pumar, M., Kowalski, L., Calavia, R., \& Llobet, E. (2016). Smart control of chemical gas sensors for the reduction of their time response. Sensors and Actuators, B: $\quad$ B $\quad$ Chemical. https://doi.org/10.1016/j.snb.2016.01.08 1

Hakim, L., \& Yonatan, V. (2017). Deteksi Kebocoran Gas LPG menggunakan Detektor Arduino dengan algoritma Fuzzy Logic Mandani. Jurnal RESTI (Rekayasa Sistem Dan Teknologi Informasi). https://doi.org/10.29207/resti.v1i2.35

Ikrom, A., Mushlihudin, M., \& Yudhana, A. (2016). Telemetri Sensor Gudang Gas LPG Berbasis ATmega 16. Jurnal Ilmiah Teknik Elektro Komputer Dan Informatika. https://doi.org/10.26555/jiteki.v2i1.4076

Lavelle, C. M. (2018). Gamma ray spectroscopy with Arduino UNO. American Journal of Physics. https://doi.org/10.1119/1.5026595

Miftakul Amin, M., Azel Aji Nugratama, M., Maseleno, A., Huda, M., \& Jasmi, K. A. (2018). Design of cigarette disposal blower and automatic freshner using MQ-5 sensor based on atmega 8535 microcontroller. International Journal of Engineering and Technology(UAE). https://doi.org/10.14419/ijet.v7i3.11917

Nurnaningsih, D. (2018). Pendeteksi Kebocoran Tabung LPG Melalui SMS Gateway Menggunakan Sensor MQ-2 Berbasis Arduino Uno. JURNAL TEKNIK INFORMATIKA. https://doi.org/10.15408/jti.v11i2.7512

Omar, A., Ditual, A., Urot, J., Dimal, M., Mamco, N., \& Sagarino, C. (2019). Mq2-Tector: an Arduino Based Gas Detector, Preventing Gas-Leak Explosion. Sensors Journal. https://doi.org/10.13140/RG.2.2.15517.5 6808

Perdana, E. M., Abdul, M., \& Yulrio, B. (2016). Rancang Bangun Pengukur Kadar Alkohol Berbasis Arduino. Coding.

Pranadji, D. K., Djamaludin, M. D., \& Kiftiah, N. (2010). Analisis Perilaku Penggunaan LPG pada Rumah Tangga di Kota Bogor. 
Jurnal Ilmu Keluarga Dan Konsumen. https://doi.org/10.24156/jikk.2010.3.2.1 72

Putra, M. F., Kridalaksana, A. H., \& Arifin, Z. (2017). Rancang Bangun Alat Pendeteksi Kebocoran Gas LPG Dengan Sensor Mq6 Berbasis Mikrokontroler Melalui Smartphone Android Sebagai Media Informasi. Informatika Mulawarman: Jurnal Ilmiah Ilmu Komputer. https://doi.org/10.30872/jim.v12i1.215
Sari, Kartika, Cucu Suhery, Y. A. (2015). Implementasi Sistem Pakan Ikan Menggunakan Buzzer Dan Aplikasi Antarmuka Berbasis Mikrokontroler. Jurnal Coding Sistem Komputer Untan.

Sudhan, R. H., Kumar, M. G., Prakash, A. U., Devi, S. A. R., \& P., S. (2015). ARDUINO ATMEGA-328 MICROCONTROLLER. IJIREEICE.

https://doi.org/10.17148/ijireeice.2015.3 406 